\title{
Türkiye'de 2009-2015 Yılları İçin Cepten Yapılan Sağlık Harcamalarının Katastrofik Etkisi
}

\section{Dilek KILIÇ ${ }^{1}$}

\begin{tabular}{l} 
ARTICLE INFO \\
\hline Article History: \\
Date Submitted: 08.06.2017 \\
Date Accepted: 01.08.2017 \\
\hline JEL Classification: \\
I14 \\
I31 \\
I32
\end{tabular}

Keywords:

Catastropic

Health Expenditure

\begin{abstract}
Sayın Kılıç, sağlık ekonomisi literatüründe sağlık hizmetleri kullanımına önem verilmesinin altında yatan temel sebebin, toplumun sağlık düzeyine olan katkısı olduğunun altını çizmiştir. Sağlık hizmetlerine erişim, bir hak olarak değerlendirildiğinde bireylerin ödeme kapasitesinin etkisinin fazla olmaması gerektiğini belirtmiş, yoksul, kırsal bölgelerde veya küçük şehirlerde yaşayan hanehalklarının ve/veya bireylerin hem nicelik hem de nitelik bakımından toplumun diğer kesimlerine kıyasla daha düşük düzeyde sağlık hizmeti kullandığının altını çizmiştir. Bu durumun iki olası sonucunu; "sağlık hizmetine ihtiyaç duyan toplumun farklı kesimlerinin sağlık düzeyleri arasında bir farklılığa neden olmakta veya sağlık düzeyleri arasında halihazırda var olan farklılığı derinleştirmekte" sözleri ile ifade etmiştir.
\end{abstract}

\footnotetext{
${ }^{1}$ Hacettepe Üniversitesi İktisadi ve İdari Bilimler Fakültesi, İktisat Bölümü Öğretim Üyesi, dbasar@hacettepe.edu.tr
} 
Sayın Kılıç, sağlık ekonomisi literatüründe sağlık hizmetleri kullanımına önem verilmesinin altında yatan temel sebebin, toplumun sağlık düzeyine olan katkısı olduğunun altını çizmiştir. Sağlık hizmetlerine erişim, bir hak olarak değerlendirildiğinde bireylerin ödeme kapasitesinin etkisinin fazla olmaması gerektiğini belirtmiş, yoksul, kırsal bölgelerde veya küçük şehirlerde yaşayan hanehalklarının ve/veya bireylerin hem nicelik hem de nitelik bakımından toplumun diğer kesimlerine kıyasla daha düşük düzeyde sağlık hizmeti kullandığının altını çizmiştir. Bu durumun iki olası sonucunu; "sağlık hizmetine ihtiyaç duyan toplumun farklı kesimlerinin sağlık düzeyleri arasında bir farklılığa neden olmakta veya sağlık düzeyleri arasında halihazırda var olan farklılığı derinleştirmekte" sözleri ile ifade etmiştir.

Genel olarak sağlık hizmetlerinin finansman yöntemlerini dört başlık altında sıralamıştır. Söz konusu finansman yöntemleri; (1) genel vergiler (2) sosyal sigorta katkı payları (3) özel sigorta katkı payları ve (4) cepten yapılan ödemeler şeklindedir. Bu noktada sayın Kılıç, genel vergilerin bir finansman yöntemi olarak daha fazla kullanıldığının bilinilirliği üzerinde durmuş ancak diğer finansman yöntemlerinin de birçok ülkede önemli ölçüde yararlanılan yöntemlerden olduğunun altını çizmiştir. Cepten yapılan sağlık harcamalarını, hanehalkları tarafından doğrudan yapılan ödemeleri temsil etmesinden hareket eden Kılıç; Çınaroğlu ve Şahin'in (2016) çalışmalarından hareketle "Gelişmişlik düzeyi düşük, sağlık sigorta sisteminin toplumun tüm kesimlerini kapsamaktan uzak olduğu, toplumun genel sağl1k düzeyinin düşük olduğu ve sosyal yardımların yeterince gelişmediği ülkelerde sağlık hizmetleri finansman yöntemleri içerisinde, hanehalkları tarafından sağlık hizmetleri için doğrudan yapılan ödemeleri temsil eden, cepten sağlık harcamalarının son derece yüksek olduğu" tespitini yapmıştır. Cepten yapılan sağlık harcamalarının artmasının hanehalklarının gerek daha nitelikli sağlık hizmetlerine erişme konusunda zorluklara sebep olması ve daha da önemlisi en temel sağlık hizmetlerine erişimi güçleştirmesi nedeniyle önemli olduğunu belirtmiştir. Bunun yarattı̆̆ en önemli sorunlardan birisinin ise "sosyal fayda" ilkesine zarar verilmesi olduğunun altını çizen Sayın Kılıç, Çınaroğlu ve Şahin'in (2016) çalışmalarında belirttiği gibi belirlenen sağlık politikaları sonucunda toplumun ekonomik açıdan dezavantajlı gruplarının refah seviyesinin azalmasının, ülke genelinde ekonomik ve refah göstergelerinde düşüşü beraberinde getirdiğini belirtmiştir. 
Cepten sağlık harcaması miktarının artışı sonucunda hanehalklarının karşı karşıya kaldıkları finansal açıdan zorlayıcı durumlar; katastrofik ve yoksullaştırıcı etki olmak üzere iki özel duruma ayrıştıran Kılıç, cepten yapılan sağlık harcaması miktarındaki artışların, hanehalklarını en temel ihtiyaçlarını karşılamak noktasında zor durumda bıraktığında katastrofik etki yaratmakta olduğunu ve bu etkinin hanehalklarıın borçlandırdığında veya finansal açıdan zorladığında ise yoksullaştırıcı etki ortaya çıkarttığını belirtmiştir. Bu konudaki literatürde üzerinde anlaşılmış bir tanım ve oran bulunmadığını ve genel olarak hanehalkının cepten yaptığı toplam sağlık harcamasının, hanehalkının toplam gelirinin belli bir yüzdesinden fazla olduğu durumda hanehalkının katastrofik bir harcama yaptığının kabul edildiğini belirtmiştir.

Litaretürde konunun tartışmalı boyutunu yukarıdaki şekilde ifade eden Kılıç, katastrofik sağlık harcamalarının arkasında yatan temel nedenin, sağlık hizmetleri kullanımındaki hakkaniyet konusu olduğunun altını çizmiştir. Bu konuda dikey hakkaniyet ve yatay hakkaniyet ayrımından hareket etmiş ve bireylerin ihtiyaç duydukları sağlık hizmetinden faydalanırken ödeme güçlerine göre sağlık bakım masraflarına katkıda bulunmalarını salık veren dikey hakkaniyetin önemini vurgulamıştır. Bir sağlık sisteminin adaletli olabilmesi için cepten yapılan harcamaların finansal açıdan yıkıcı olmaması gerekliliğini belirtmiştir. Sağlık ekonomisi konusundaki politika raporlarının altını çizdikleri hanehalklarının yüksek düzeylerdeki sağlık harcamalarından korunması gerekliliği hususunun önemini özellikle adil finansman bağlamında ele alan Kılıç, Dünya Sağlık Örgütü'nün 2000 yılında yayınlamış olduğu raporunda sağlık sistemlerinde adil finansman tanımını referans olarak almıştır: "Her bir hanehalkının sağlık bakım masrafları nedeniyle karşı karşıya kaldığı risk, hastalık riski yerine ödeme yapma kabiliyetine göre dağıtılmalıdır. Yani adil finansmanı sağlamak için sağlık sistemleri herkes için finansal korumayı (financial protection) garanti etmelidir.” (s. 35). Raporun özellikle sağlık sisteminin, bireylerin ihtiyaç duyduğu sağlık hizmetini satın alması sonucunda yoksullaşmasına veya yüksek maliyetlerden dolayı ihtiyaç duyduğu sağlık hizmetini satın alamamasına neden oluyorsa adaletsiz olduğuna yönelik argümanını da özellikle belirtmiştir.

Uluslararası Çalışma Örgütü’nün 2002 tarihli raporunda yer alan, bir sağlık sisteminin, sağlık ödemesi sonucunda hiç kimsenin fakirleşmemesi gerektiğini garanti etmesi gerekliliğinin 
önemi Sayın Kılıç tarafından ifade edilmiştir. Aynı raporda finansal koruma; "sağlık sistemini finanse etmek için hanehalkları veya bireyler gelirlerinin makul bir oranından daha fazlasından feragat etmek zorunda kalmamaları" sözleri ile belirtilmiştir.

Katastrofik harcamanın büyüklüğü ya da finansal koruma konusunda bireylerin gelirlerinin ne kadarından feragat edecekleri konularının iyi tanımlanmış olmasına rağmen çok da açık olmadığını vurgulayan Kılıç, bunun nedeninin, doğrudan konuya ilişkin hesaplamalarda yattığını belirtmiştir. Hesaplamalar yapılırken paydada kullanılacak değerin hanehalkının toplam gelirinin mi (total income) olacağı, yoksa toplam harcanabilir gelirinin mi (total disposable income) kullanılacağı konusunun tartışmalı olduğunu hatırlatan Kılıç, bu çerçevede Dünya Sağlık Örgütü harcanabilir toplam geliri “ödeme kapasitesi” (capacity to pay) olarak adlandırmakta ve toplam gelirden temel ihtiyaçlara yönelik harcama değeri çıkarıldıktan sonra kalan değer olarak tanımladığını belirtmiştir. Buna göre yapılan çalışmalarda payda değeri olarak genellikle toplam gelirden gıda harcamaları çıkarıldıktan sonra kalan değerin kullanıldığını ifade etmiştir.

Katastrofik sağlık harcamasının tespitinde iki yaklaşım olduğunu belirten Kılıç, söz konusu yaklaşımların harcama yaklaşımı ve gelir yaklaşımı olduğunun altını çizmiştir. Harcama yaklaşımına göre katastrofik sağlık harcaması; cepten yapılan sağlık harcamalarının kişilerin yaşantılarını sürdürebilmek için yaptıkları temel harcamaların dışında kalan toplam harcamalarının belirli bir kısmını aşması durumunda (belirli bir eşik değeri geçmesi) ortaya çıktığını ifade etmiştir. Geliri yaklaşımına (ödeme kapasitesi) göre ise; katastrofik sağlık harcamasının cepten yapılan sağlık harcamasının hanehalkı gelirinin belli bir yüzdesini aşması durumunda ortaya çıktığını belirtmiştir. Gelir yaklaşımında söz konusu belli bir yüzdenin düzeyi konusunun tartışmalı olduğunu, söz konusu düzeyi toplam gelirin \%5 ve \%20 arasındaki çeşitli oranları kabul eden çalışmalar bulunduğunu belirtmiştir. Kılıç bu noktada söz konusu sınır ile ilgili olarak literatürde bir fikir birliği bulunmamakla birlikte genellikle Dünya Sağlık Örgütü tarafından "adil finansman" miktarı olarak kabul edilen sınırın esas alındığını belirtmiştir. Xu ve diğerleri (2005) tarafından belirlenen metodolojiye uygun olarak hanehalklarının katastrofik ve yoksullaştırıcı etkiye maruz kalma durumlarının hesaplanmasında cepten yapılan sağlık harcamalarının ödeme gücüne (kapasitesine) oranının esas alındığını bilhassa vurgulamıştır. 
Ödeme gücünün hesaplanabilmesi için Çınaroğlu ve Şahin'in (2016) çalışmalarından hareket ederek öncelikle eşdeğer hanehalkı büyüklüğünün (eqsize) hesaplanmasına ihtiyaç duyulduğunu belirten Kılıç, eşdeğer hanehalkı büyüklüğü hanelerin yetişkin-çocuk bileşimlerindeki farklılıklar dikkate alınarak farklı büyüklük ve bileşimlerdeki hanehalkları arasında karşılaştırmalara imkan sağladığını vurgulamıştır. Bunun için her bir hanehalkı büyüklüğünün kaç yetişkine (eşdeğer fert sayısı) denk olduğunu belirlemek amacıyla eşdeğerlik ölçeği hesaplandığını ve sonrasında ise yoksulluk sınırının hesaplanması gerektiğinin altını çizmiştir. Gıda harcamasının toplam tüketim harcaması içindeki payına göre sıralı $\% 45-\% 55$ arasında kalan hanelerin, eşdeğer fert başına gıda harcamalarının ortalamasının yoksulluk sınırı olarak belirlendiğini, eşdeğer hane büyüklüklerine göre geçinme sınırı belirlendiğini ve hane harcaması, kendi eşdeğer hane büyüklüğüne göre belirlenen yoksulluk sınırından küçük olan hanelerin "yoksul" olarak nitelendirildiğini belirtmiştir. Hanenin ödeme kapasitesi hanenin geçinme sınırı dışında kalan harcaması olarak tanımlanmasından hareketle, hanenin ödeme kapasitesi bulunduktan sonra sağlık harcamasının ödeme kapasitesine oranının hesaplanabildiğini belirtir.

Katastrofik sağlık harcaması yapanları bulmak için ise sağlık harcamasının ödeme kapasitesine oranı \%40 ve daha büyük olan haneler, "katastrofik sağlık harcaması yapan haneler" olarak nitelendirildiğini belirten Kılıç, sağlık harcaması nedeniyle yoksullaşan hanelerin bulunmasında ise yoksul olmayıp (yani harcaması, kendi eşdeğer hane büyüklüğüne göre belirlenen geçinme sınırından büyük olup) sağlık dışında kalan harcaması, kendi eşdeğer hane büyüklüğüne göre belirlenen geçinme sınırından küçük olan hanelerin, "katastrofik sağlık harcaması nedeniyle yoksullaşan haneler" olarak nitelendirildiğini belirtmiştir.

Sayın Kılıç katastrofik sağlık harcamalarının hesaplanması ve belirlenmesi konusundaki kavramsal çerçeveyi sunduktan sonra litertürde yapılan çalışmalara ve söz konusu çalışmaların karşılaştıkları temel sorun olan seçim yanlılığı konusunu ele alarak değerlendirmelerine devam etmiştir. Kılıç'a göre cepten yapılan sağlık harcamalarını inceleyen çalışmaların en önemli eksikliği, hanehalklarının sağlık hizmeti kullanımının gerektirdiği cepten yapılan sağlık harcamasını karşılayamayacağını düşündüğü için sağlık hizmetini hiç kullanmamayı tercih etmesi durumunu analize dahil etmemeleridir. Böylece örneklemin sadece sağlık hizmeti kullanarak cepten harcama yapan hanehalklarını içereceğini ve bu durum yapılan ampirik 
çalışmalarda örneklem seçim yanlılığına (sample selection bias) neden olacağının üzerinde durmuştur. Bu problemin elde edilen analiz sonuçlarının hatalı olmasına (yanlı olmasına) yol açabileceğini belirten Kılıç, bu sorunu aşmak için anketlerde, "hiç ihtiyaç duyduğunuz halde sağlık hizmeti kullanamadığınız bir durum oldu mu" benzeri sorularla bu eksikliğin giderilmeye çalışılabileceğini belirtmiştir. Bu problemi gidermek için kullanılabilecek yöntemlerden bir diğeri ise bu sorunu göz önüne alan Heckman seçim modeli (1979) gibi ekonometrik modelleri tercih etmek olabileceğini belirten Kılıç, ancak seçim modellerinin genellikle seçim denklemi için kullanılacak fazladan bir değişken (enstrüman değişken) gerektirmekte oluşunu ve veri kısıtına sahip olmasının bu yöntemlerin kullanılması önünde bir engel oluşturduğunun altını çizmiştir. Birçok veri seti bireylerin/hanehalklarının doğrudan sağlık hizmeti kullanıp kullanmama durumuna ilişkin veya eğer sağlık hizmeti kullanıldıysa hangi tip sağlık hizmeti kullanıldığına ilişkin detaylı bilgi içermemesinin de önemine değinmiştir.

Literatürde yer alan üç önemli çalışmaya değinen Kılıç, öncelikle sağlık harcamalarının sosyo-ekonomik dağılımının ülkeden ülkeye farklılıklar gösterdiği bulgusuna dayanan ve sekiz gelişmekte olan ve geçiş dönemindeki ülkelerin anket verilerini kullandıkları ancak ülkeler arasında birbiriyle benzer nitelikli sonuçlara ulaşamadıkları Makinen ve ark (2000) çalışmasını ele almıştır. Çalışmanın sonuçlarına göre Burkina Faso, Paraguay ve Tayland'da regresif bir trend bulunurken (yani zengin hanehalkları yoksullara göre toplam tüketimlerinin daha düşük bir yüzdesini sağlık harcamalarına ayırmaktadırlar), buna karşılık Guatemala ve Güney Afrika'da progresif eğilim tespit edilmiştir. Kılıç'a göre çalışmanın en önemli sonuçlarından biri; zengin hanehalklarının ihtiyaç duyduklarında sağlık hizmetleri kullanma olasılığg yoksul hanehalklarına göre daha fazla olmasıdır. Ancak bu durumun nedeninin yoksul hanehalklarının sağlık harcamalarını ödeyemeyeceklerini düşündükleri için hiç sağlık hizmeti kullanmamalarından kaynaklanıyor olmasının da muhtemel olduğunu belirten Kılıç, bu çerçevede, cepten yapılan sağlık harcamalarını inceleyen çalışmaların en önemli eksikliğinin, hanehalklarının sağlık hizmeti kullanımının gerektirdiği cepten yapılan sağlık harcamasını karşılayamayacağını düşündüğü için sağlık hizmeti kullanmamayı tercih etmesi durumunu analize dahil etmemeleri şeklinde yukarıda belirttiği seçim yanlılığı sorunu olduğunu bir kez daha belirtmiştir. 
Kılıç'ın ele aldığı ikinci çalışma ise 59 ülke için katastrofik sağlık harcaması düzeylerine ve belirleyenlerinin ele alındığı Xu ve arkadaşlarının (2003) çalışmasıdır. Bu çalışmanın özelliğinin eşik değeri toplam gıda dışı harcamaların \%40’1 olarak ele alması olduğu Kılıç tarafından özellikle belirtilmiştir. Kılıç çalışmanın önemli olan hususlarından biri gelişmiş sosyal güvenlik sistemlerine sahip olan Kanada, Çek Cumhuriyeti, Danimarka, İngiltere, Almanya ve Fransa gibi ülkelerde katastrofik sağlık harcaması \%0.1'in altında iken katastrofik sağlık harcamaları bazı geçiş ülkelerinde, orta-gelirli ve düşük gelirli ülkelerde ve bazı Latin Amerika ülkelerinde yüksek çıkmasıdır. Örneğin Vietnam ve Brezilya'da \%10'nun üzerinde iken, Azerbaycan ve Kolombiya'da \%5'in üzerinde olmasını özellikle belirtmiştir. Kılıç'a göre çalışmanın önemli özelliklerinden biri yazarların aynı zamanda belirleyenlere de bakmış olmaları ve katastrofik hanehenalkı yüzdesi ile ulusal sağlık harcamaları içinde cepten yapılan sağlık harcamaları oranı arasında güçlü ve pozitif bir ilişki bulmaları ve bunun yanı sıra katastrofik hanehenalkı yüzdesi ile GSYİH içinde toplam sağlık harcamaları payının ve yoksulluk sınırının altında yaşayan hanehalkı yüzdesinin pozitif ilişkili olduğu sonucuna ulaşmalarıdır. Kılıç çalışmada genel olarak yoksul gelir gruplarının daha fazla katastrofik sağlık harcamalarına maruz kaldıklarını dair ilginç olan bulgunun, en yüksek katastrofik sağlık harcamasının en düşük gelir grubuna ait olmaması olduğunu belirtmiş ve bunun sebebinin yine seçim problemi olduğunu belirtmiştir. Kılıç'ın sözleri ile "Bu hanehalkları yüksek maliyetlerden ötürü ihtiyaç duysalar bile sağlık hizmeti kullanmamayı tercih etmiş olabilirler".

Kılıç'ın ele aldığı üçüncü çalışma ise Wagstaff ve Doorslaer (2003) çalışmasıdır bu çalışmada katastrofik sağlık harcamasının tanımı ve ölçümü için kukla değişken oluşturmaya dayanan iki alternatif yaklaşım geliştirdiklerini belirmiştir. Birinci yaklaşım toplam harcama veya gelirin belli bir eşik değerinin üzerinde olan cepten yapılan sağlık harcaması katastrofik olarak nitelendirilmesine dayalı olduğunu belirten Kılıç, ikinci yaklaşımın ise hanehalkının cepten yaptığı sağlık harcamaları neticesinde yoksullaşıp yoksullaşmadığı veya yoksulluğunun derinleşip derinleşmediğini gösteren bir kukla değişsen oluşturulduğunu ifade etmiştir. $\mathrm{Bu}$ çerçevede, yazarlar katastrofik sağlık harcamalarının sıklığı ve yoğunluğuna ve yoksulluk etkisinin sıklığına ve yoğunluğuna ilişkin endeksler geliştirdiklerini ve bu yöntemleri 1993 ve 1998 yılları için Vietnam için hesapladıkları bilgisini paylaşmıştır. Çalışmanın sonuçlarına bakıldığında, toplam bütçesinin \%5'inden fazlasını sağlık harcamalarına ayıran hanehalkı yüzdesi 1993'te \%38 gibi yüksek bir oran olduğunu, bu oranın 1998'de \%33'e düştüğünü 
belirtmiştir. Bulguların sağlık harcaması yüzünden bazı hanehalklarının yoksul değil iken yoksullaşmaktan ziyade halihazırda yoksul olan hanehalklarının daha da yoksullaştığını göstermekte olduğunu belirtmiştir.

Hacettepe Üniversitesinden Selcen Öztürk'le yaptıkları çalışmanın ampirik analizde 2009-2015 dönemi için toplam yedi yıllık Hanehalkı Bütçe Anketini (Household Budget Survey) kullandıklarını belirten Kılıç, Türkiye İstatistik Kurumu (TÜİK) tarafından yapılan ve tüm ülkeyi temsil eden Hanehalkı Bütçe Anketlerinin (HBA), her yıl farklı hanehalkları ile tekrarlandığını bu durumun aynı hanehalkını yıllar itibariyle takip eden panel veri özelliğine engel olduğunu belirtmiş ve bunun da söz konusu anketlerin önemli bir eksikliği olduğunun altını çizmiştir.

Literatürde katastrofik sağlık harcamasının üzerinde uzlaşılmış bir tanımı ve hesaplama yönetimi olmadığını yeniden belirten Kılıç, çalışmalarında, ödeme kapasitesi yönteminin kullanılmış olduğunu ve hanehalkının toplam harcamasından toplam gida harcaması çıkarıldıktan sonra kalan değerin, hesaplamalarda payda değeri olarak kullanıldığını belirtmiştir.

Regresyonun bağımlı (açıklanan) değişkeni, hanehalkının toplam cepten yaptığı sağlık harcaması miktarının eşik değerden yüksek olduğu durumda 1 değerini, olmadığında ise 0 değerini aldığını belirten Kılıç, söz konusu bağımlı değişken kesikli (discrete) olduğu için böyle durumlarda sıklıkla tercih edilen standart probit modelin tahmin edildiğinin altını çizmiştir.

Analizde hanehalkı düzeyinde kullanılan bağımsız değişkenler olarak ise hanehalkı reisinin sağlık sigortasına sahip olmaması durumunu, hanehalkı resinin erkek olduğu durumu, evde engelli ve/veya hasta bir bireyin bulunması durumunu ve yerleşim yerinin kentsel bölge olduğu durumunu gösteren kukla değişkenler kullanıldığını belirtmiş ve bunların dışında hanehalkı reisinin sahip olduğu en yüksek eğitim düzeyi ve çalışma durumunun da bağımsız değişkenler olarak analize dahil edildiğini eklemiştir.

Analizin en önemli bağımsız değişkenlerinden biri de hanehalkının yoksul bir hanehalkı olup olmadığını gösteren kukla değişken olduğunu ve söz konusu değişkenin OECD’nin göreli yoksulluk tanımına göre oluşturulduğunun altını çizen Kılıç, bir hanehalkının eşit veya dengeli 
toplam harcama değeri (eqilivalised total expenditure), tüm hanehalklarının eşit veya dengeli toplam harcamasının medyan değerinin (equilivalised median total expenditure) \%60'1n1 geçmiyorsa o hanehalkı "yoksul” olarak değerlendirildiğini ve kukla değişkenin bu hanehalk1 için 1 değerini aldığını belirtmiştir. Bu değişkenlere ek olarak evde bulunan okul öncesi çocuk sayısı (5 yaş ve altı), 6-14 yaş arasındaki çocuk sayısı ile yaşlı hanehalkı üye sayısı (65 yaş ve üstü) ile hanehalkı büyüklüğü de analizin bağımsız değişkenleri arasında yer aldığını vurgulayan Kılıç, zaman boyutununun da analize dâhil edilmesi için her bir yılın kukla değişken olarak çalışmaya eklenmiş olduğunu ve 2002 yılının ise referans yıl olarak kullanıldığını belirtmiştir.

Kılıç, seçim yanlılığı probleminin kendi çalışmalarında da bir sorun olarak karşılarına çıktığını belirtmiştir. Bunu gidermek için kullanılacak yöntemin uygulanmasını sağlayacak yöntemin gerektirdiği verilerin olmaması önemli bir kısıt oluşturduğunu belirten Kılıç, söz konusu kısıtı; hane halkının sağlık hizmeti kullanıp kullanmamasını etkileyen ama hanehalkının katastrofik etkiye maruz kalıp kalmadığını etkilemeyen bir değişken bulmak gerekliliğinin altını çizmiş ve söz konusu değişkenin mevcut verilerle bulunamadığını belirtmiştir. Çalışmada \%2,5-20 arasında değişen 5 farklı eşik değer kullanıldığını belirten Kılıç çalışmanın sonuçlarını aşağıdaki tablo ile sunmuştur:

Tablo 1 - Çeşitli Eşik Değerler Düzeyinde Katastrofik Harcama Oranları

\begin{tabular}{|l|l|l|l|l|l|}
\hline Yillar & $\mathbf{\% 2 . 5}$ & $\mathbf{\% 5}$ & $\mathbf{\% 1 0}$ & $\mathbf{\% 1 5}$ & $\mathbf{\% 2 0}$ \\
\hline $\mathbf{2 0 0 9}$ & 17.11 & 9.26 & 3.98 & 2.42 & 1.43 \\
\hline $\mathbf{2 0 1 0}$ & 22.7 & 12.76 & 5.08 & 2.61 & 1.52 \\
\hline $\mathbf{2 0 1 1}$ & 20.65 & 10.24 & 3.55 & 1.71 & 0.98 \\
\hline $\mathbf{2 0 1 2}$ & 18.92 & 9.25 & 3.57 & 1.82 & 0.94 \\
\hline $\mathbf{2 0 1 3}$ & 23.00 & 11.34 & 4.12 & 1.90 & 0.99 \\
\hline $\mathbf{2 0 1 4}$ & 21.75 & 11.34 & 4.19 & 2.05 & 1.09 \\
\hline $\mathbf{2 0 1 5}$ & 20.28 & 10.91 & 4.14 & 1.99 & 1.14 \\
\hline
\end{tabular}

Kılıç, Katastrofik sağlık harcamalarının 2013 de artış trendi gösterdiği ve 2014-15 döneminde ise çok ufak bir azalma görüldüğünü belirtmiştir. 2003 yılından itibaren başlayan sağlıkta dönüşüm programının cepten yapılan sağlık harcamaları üzerinde çok önemli etkisi olduğunu belirtir. Yoksul grupta sigorta kapsamının \%20'den \%85'e çıktığının altını çizmiştir. 
Yoksul hanehalklarının katastrofik sağlık harcama yapma olasılığının daha düşük çıktığını belirtmiştir. Yoksulluktan sonra en önemli değişken evde engelli bireyin olması durumu olduğuna dair sonuç olduğunu ve eğitimle katastrofik sağlık harcaması arasında pozitif ilişki, çalışmayanlar durumunda yine pozitif ve yaşlı bireyler durumunda yine pozitif ilişki bulunduğunu belirtmiştir.

Sonuç olarak, Türk sağlık sisteminde 2003 yılından beri uygulanan sağlık politikalarının etkilerinin dikey hakkaniyet konusu da gözetilerek daha dikkatli ele alınması gerektiğinin belirten Kılıç, özellikle katastrofik sağlık harcamalarına ilişkin olarak konunun her boyutuyla ele alınmasını sağlayacak yeni yöntemler geliştirilmesi gerekliliğinin altını çizmiştir, Seçim yanlılı̆̆ı probleminin araştırılma zorunluluğunu belirten Kılıç, daha sağlıklı sonuçlar elde etmek için bu sorunun üstesinden gelecek yeni yöntemler bulunması gerekliliğinin altını çizmiştir. 